Conclusion In keeping with previous UK surveys, the majority of isolates in our population were pulmonary with MAI being the most frequently seen species of NTM. In those in whom treatment was indicated low eradication rates and significant relapse rates confirm complexity of managing this population of patients.

\section{NTM Species}

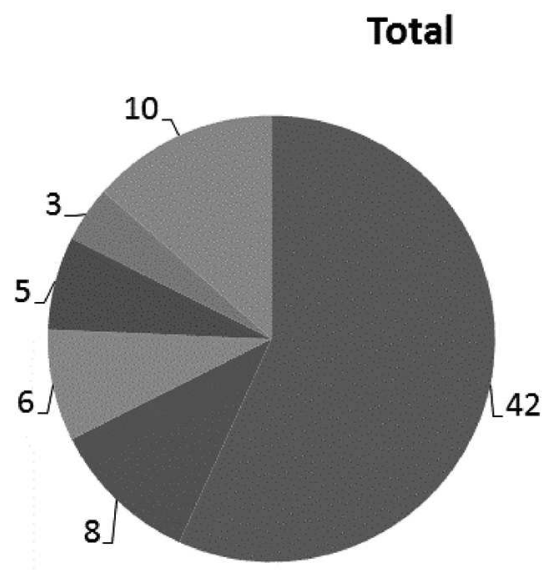

MAl

M. Chelonae

M. Xenopi

M. Abscessus

M. Malmoense

Other

Abstract P115 Figure 1

\section{COPD: Causes and Consequences}

\section{P116 OBSERVATIONAL STUDY TO CHARACTERISE 24-HOUR COPD SYMPTOMS: CROSS-SECTIONAL RESULTS FROM THE ASSESS STUDY}

${ }^{1} \mathrm{M}$ Miravitlles, ${ }^{2} \mathrm{H}$ Worth, ${ }^{3}$ J Soler-Cataluña, ${ }^{4} \mathrm{D}$ Price, ${ }^{5} \mathrm{~F}$ De Benedetto, ${ }^{6} \mathrm{~F}$ Roche, ${ }^{7} \mathrm{~N}$ Skavalan Godtfredsen, ${ }^{8} \mathrm{~T}$ van der Molen, ${ }^{9} \mathrm{C}$ Löfdahl, ${ }^{10 \mathrm{~L}}$ Padullés, ${ }^{10} \mathrm{~A}$ Ribera; ${ }^{1}$ Hospital Universitari Vall d'Hebron, Barcelona, Spain; ${ }^{2}$ Klinikum Fürth, University ErlangenNürnberg, Fürth, Germany; ${ }^{3}$ Hospital General de Requena, Valencia, Spain; ${ }^{4}$ University of Aberdeen, Aberdeen, UK; ${ }^{5}$ Ospedale Clinicizzato SS. Annunziata, Chieti, Italy; ${ }^{6}$ Cochin Hospital, University Paris Descartes, Paris, France; ${ }^{7}$ Bispebjerg University Hospital, Copenhagen, Denmark; ${ }^{8}$ University of Groningen, University Medical Center Groningen, Groningen, The Netherlands; ${ }^{9}$ Lund University Hospital, Lund, Sweden; ${ }^{10}$ Almirall R\&D Centre, Barcelona, Spain

\subsection{6/thoraxjnl-2013-204457.266}

Introduction and Objectives Little is known about the 24-hour profile of COPD symptoms. This study assessed the frequency/ severity of 24-hour symptoms and their impact on patients' wellbeing.

Methods This cross-sectional, observational study was conducted in patients with stable COPD. Baseline night-time, earlymorning and day-time symptoms (symptom questionnaire), dyspnoea (modified Medical Research Council dyspnoea scale [mMRC]), health status (COPD Assessment Test [CAT]), anxiety/ depression levels (Hospital Anxiety and Depression Scale [HADS]) and sleep quality (COPD and Asthma Sleep Impact Scale [CASIS]) were assessed. Primary endpoint: baseline frequency, severity and inter-relationship of night-time, early-morning and day-time symptoms; secondary endpoints: relationship between 24-hour symptoms and dyspnoea, health status, anxiety/ depression and sleep quality.

Results 727 patients were recruited from eight countries: 65.8\% male, mean \pm SD age $67.2 \pm 8.8$ years, mean \pm SD $\%$ predicted
$\mathrm{FEV}_{1} 52.7 \pm 20.6 \%$. Early-morning/day-time symptoms were most frequent; however night-time symptoms were common (Table). Symptom severity was comparable during the nighttime, early-morning and day-time. In the week prior to baseline, $56.7 \%$ patients had symptoms throughout the 24-hours $(79.9 \%$ in 2 or 3 parts of the day). Breathlessness was most common $(71.4 \%$ patients); its prevalence increased throughout the 24-hours $(32.1 \%$ night-time, $51.6 \%$ early-morning, $65.2 \%$ daytime).

Dyspnoea, health status, anxiety/depression and sleep quality were worse in patients with night-time, early-morning or daytime symptoms versus patients without symptoms in each period (all $\mathrm{p}<0.001$ ). Most patients with more severe dyspnoea (mMRC scale $\geq 2$ ) had 24-hour symptoms (range 61.5-68.2\%); patients with 24-hour symptoms had the worst health status (mean CAT score 20.0 vs range 8.1-14.9 in all other patients). Patients with any combination of night-time/early-morning symptoms had the highest anxiety (mean HADS scores 6.7-7.5 vs 3.6-5.8 in patients without this combination); depression levels were lowest in patients with no symptoms/only early-morning symptoms (mean HADS scores 4.2-5.4 vs 6.5-7.8 in all other patients). Patients with any night-time symptom had worse sleep quality than patients without night-time symptoms (mean CASIS scores 41.6-51.1 vs 31.6-35.5).

Conclusions Most patients had COPD symptoms throughout the 24-hours. Dyspnoea, health status, anxiety/depression levels and sleep quality were significantly worse in patients who had symptoms in any part of the day.

\begin{tabular}{|c|c|c|c|}
\hline $\mathrm{N}=727$ & Night-time & Early-morning & Day-time \\
\hline \multicolumn{4}{|c|}{ Prevalence of COPD symptoms, n (\%) } \\
\hline$\geq 3$ times during the past week & $312(42.9)$ & $455(62.6)$ & $427(58.7)$ \\
\hline$\geq 3$ times during a typical week ${ }^{a}$ & $378(52.0)$ & $488(67.1)$ & $468(64.4)$ \\
\hline $\begin{array}{l}\geq 1 \text { COPD symptoms during } \\
\text { the past week }\end{array}$ & $458(63.0)$ & $592(81.4)$ & $601(82.7)$ \\
\hline \multicolumn{4}{|l|}{ Severity of COPD symptoms, ${ }^{b} \mathrm{n}\left(\%^{\mathrm{c}}\right)$} \\
\hline Mild & $191(46.7)$ & $252(44.1)$ & $254(43.1)$ \\
\hline Moderate & $175(42.8)$ & $250(43.8)$ & $272(46.2)$ \\
\hline Severe & $39(9.5)$ & $61(10.7)$ & $59(10.0)$ \\
\hline Very severe & $4(1)$ & $8(1.4)$ & $4(0.7)$ \\
\hline
\end{tabular}

${ }^{a} \mathrm{~A}$ typical week refers to a week that the patient considers is most usual for them during the previous month

${ }^{\mathrm{b} D}$ During the previous week

CPercentage based on patients who reported symptoms in the previous week and provided data for symptom severity

\section{P117 COMPARISON OF RESPIRATORY-RELATED QUALITY OF LIFE PULMONARY REHABILITATION OUTCOMES AND DURATION OF TREATMENT IN ACUTE AND COMMUNITY SETTINGS}

${ }^{1} \mathrm{JMS}$ Cox, ${ }^{2} \mathrm{H}$ Matthews, ${ }^{3} \mathrm{P}$ Browne, ${ }^{2} \mathrm{~A}$ Blackburn; ${ }^{1}$ Norfolk County Council, Norwich, UK; ${ }^{2}$ James Paget University Hospitals NHS Foundation Trust, Gorleston, UK; ${ }^{3}$ Norfolk and Norwich University Hospitals NHS Foundation Trust, Norwich, UK

\subsection{6/thoraxjnl-2013-204457.267}

Introduction and Objectives NICE guidance recommends that patients are offered between six and twelve weeks of pulmonary rehabilitation as effective treatment option for chronic obstructive pulmonary disease (NICE, 2010). While there is good 